\title{
Designing Teaching Practice in Post-Graduate Education
}

\author{
Astrid M. Sølvberg, Marit Rismark \\ Department of Education and Lifelong Learning, Norwegian University of Science and Technology, NTNU, \\ Trondheim, Norway \\ Email: astrid.solvberg@ntnu.no, marit.rismark@ntnu.no
}

Received 19 May 2016; accepted 31 July 2016; published 3 August 2016

Copyright (C) 2016 by authors and Scientific Research Publishing Inc.

This work is licensed under the Creative Commons Attribution International License (CC BY). http://creativecommons.org/licenses/by/4.0/

(c) (i) Open Access

\section{Abstract}

This paper explores how teachers can design post-graduate teaching practice in ways that allow participants to construct new knowledge that supports their daily work practice. To explore the design of teaching practice in post-graduate education, the authors have studied a post-graduate course at the Norwegian University of Science and Technology, NTNU. Qualitative data about the teaching practice were collected through observations and interviews. The data were analysed using an inductive collaborating coding procedure involving descriptive and interpretive phases. Two overarching categories were evident in the data material. The category Joint Workplace Experience describes the participants' joint experiences of their work practice. The category Inclusion of Workplace Experience in Teaching Practice describes recurring regularities of how the participants' workplace experience was included in the teaching practice. Based on the findings we present a teaching design that may assist teachers in designing a teaching practice to satisfy the competence development needs that workers have. Bearing this design in mind, we first argue that teachers need to acknowledge the role of experience for learning. Second, they need knowledge about what constitutes joint workplace experience for the specific group of participants in the course they are teaching. Third, teachers need to include this knowledge when they design the teaching practice.

\section{Keywords}

Lifelong Education, Post-Graduate Education, Teaching Design, Professional Training, Workplace Experience

\section{Introduction and Theoretical Background}

European lifelong learning policies emphasize the need and demand for new competence in society. In answer to 
this, universities and colleges have facilitated numerous post-graduate education programmes to address the competence development needs of the workforce. There are concerns, however, that there is a gap between what practitioners do in their everyday work and what they are asked to learn when attending post-graduate education (e.g. Noda \& Kim, 2014; Roth, 2010). In this paper we explore how teaching practice in post-graduate education may be designed to reduce this gap. We report findings from a study of teaching practices in a post-graduate course that was established to address the competence development needs of employees within the energy sector in Norway. The study was guided by the following research question: how can teachers design post-graduate teaching practice in ways that allow participants to construct new knowledge that supports their daily work practice?

One of the main arguments in the paper is that teachers need to emphasize the role of experience for learning when they design teaching practices to meet the competence development needs that workers have. The connection between experience and learning has been well documented for centuries, from Greek philosophers to Dewey and Lindeman, and numerous theoretical articles underscore the fundamental role that experience plays in learning in adulthood. According to Kolb (1984: p. 38), learning "is the process whereby knowledge is created through the transformation of experience”. It is a person's repertoire of examples, images, understandings and actions that forms his or her experience (Schön, 2002). Dewey (1938) postulates that experience must exhibit two major principles if learning is to take place: continuity and interaction. The principle of continuity of experience means that a learner must connect what is learned from current experience to experiences in the past, and must also be able to see possible future implications. The principle of interaction emphasizes the importance of the situation when it comes to learning, positing that "an experience is always what it is because of a transaction taking place between an individual and what, at the time, constitutes his environment” (Dewey, 1938: p. 41).

Various conceptualizations of the relationship between experience and learning are reflected in the term "experiential learning” (Merriam \& Bierema, 2014). Using a constructivist view of learning, Kolb and Kolb (2005: p. 194) make distinct postulations as to what experiential learning theory involves. They argue that learning is best conceived as a process, not in terms of outcomes. Moreover, learning requires various modes of reflection, action, feeling and thinking, as well as interactions between the learner and the environment. These propositions are evident in several models of experiential learning (Merriam, Caffarella, \& Baumgartner, 2007). For example, in his model of experiential learning Kolb (1984), building on the work of Dewey, claims that learning from experience may be perceived as a four-step process, a learning cycle, moving from concrete experience via reflective observation and abstract conceptualization, to active experimentation and back to concrete experience. Fenwick (2003) argues that Kolb’s model does not take the learner's context into consideration and that experience and reflection seem to exist in a vacuum. Jarvis (1987) used Kolb’s model as a benchmark for deriving a nine-stage model of experiential learning. He (Jarvis, 2006) finds three main types of learning from experiences; non-learning (the person presumes to already know or rejects the opportunity to learn from the situation), nonreflective learning (remembering an experience and repeating it or following orders) and reflective learning (planning, monitoring and reflecting upon experiences). Jarvis contributes new theoretical insights on the process in which the "whole person" engages in an experience, cognitively as well as emotionally and practically through his or her individual biography. In this way he addresses some of Kolb’s shortcomings by proposing that the person brings his or her biography into the situation.

Together, the models provide conceptual frameworks that focus on different aspects of learning from experience. These conceptual frameworks may inspire teachers when they make decisions on their teaching practice. Naturally, teaching designs will vary according to the lenses through which teachers understand learning and the role of experience in learning. According to Kolb \& Kolb’s (2005) postulations on experiential learning theory, various modes of reflection, action, feeling, thinking and interaction may be seen as cornerstones in teaching practice. According to a constructivist perspective, teaching practice should be designed to foster critical reflection on experience, as people reflect on concrete experiences and construct new knowledge as a result of their reflections. Furthermore, learners' assumptions should be challenged and personally constructed knowledge should be validated (Fenwick, 2003). Bearing this line of thinking in mind, teaching practices need to invite students into learning environments that allow them to become involved in new experiences, encourage them to view new experiences from a variety of perspectives, inspire them to create integrative ideas and concepts, and foster the ability to apply new ideas in actual practice (Kolb, 1984; Merriam, Caffarella, \& Baumgartner, 2007). In such teaching practices, teachers will serve as facilitators for reflection by encouraging learners to discuss and reflect on concrete experiences in a trusting, open environment. 


\section{Methodology}

To explore the design of teaching practice in post-graduate education we have studied a post-graduate course at the Norwegian University of Science and Technology, NTNU. The course that we studied was established to meet a comprehensive training need of employees in the power-supply industry in Norway. Because the global energy situation demands smarter consumption of energy, new developments within energy production, infrastructure, transmission and distribution of electricity energy systems are being made. This new knowledge needs to be made available to the employees working in the power companies

(www.smartgrids.eu; www.smartgrids.no/english).

The course was held twice, in 2013 and 2014. Altogether 32 students, employed at various power companies across Norway, attended the course. The participants had a variety of professional backgrounds, all at the Master's degree level, such as in economics, ICT, telematics and engineering. With two exceptions, the participants had more than five years of work experience. Twenty-one upfront scientists were recruited to teach in the course. The large number of teachers was needed to cover the latest developments within the field.

On the overriding level, the course was organized as a flexible continuing education programme, as a credit course lasting for one semester. Students attended lectures at the university on two separate occasions (a week each time) during the study period. Their employers encouraged them to participate and covered travel costs and university fees. The course participants were also given opportunities to study at the workplace during regular work hours. The study-programme design and the employer support enabled the power-industry employees to combine work and education.

We observed the teaching practice during the course lectures. All in all we observed 125 lectures (each lasting 45 minutes) throughout the two courses. We both sat in and jointly observed the teaching practice. This involved observing the organization of course activities, student involvement and ways in which the teachers facilitated reflections. The observations gave us first-hand information about the teaching practice. However, observation alone does not provide insight into how participants understand social activities (Patton, 1990). We therefore carried out 13 semi-structured interviews with participants. The interviews were based on themes derived from the previous observations and enabled us to elaborate and clarify multiple aspects of how the participants experienced the teaching practice. We collaborated closely in planning the interviews and we were both active contributors in the interview situation. The interviews lasted up to one hour and were recorded and thoroughly transcribed.

The data analysis involved the interplay between the researchers, transcribed data material and theory. Theoretical assumptions about learning and experience provided a point of departure for the development and exploration of categories during the data analysis. Such grounding in the literature may counteract bias by expanding the researcher's understandings of multiple ways of viewing the phenomenon (Morrow, 2005). During the data collection phase we tracked analytical insights into how teaching practice in post-graduate education may be designed according to knowledge about experience and learning and these insights were, as such, part of the field work and the beginning of the qualitative analysis (Patton, 2015). During the analysis we moved back and forth between the transcribed texts and theoretical assumptions on experience and learning. We aspired to maintain a certain degree of rigor through the establishment of work procedures for the mutual construction of meaning between co-researchers. For the first reading of the data we read all the field notes and interviews individually and made comments in the margins that expressed our preliminary notions about what the data contained. This was an initial attempt at organizing the data. Next, we compared and discussed similarities and differences. Then new readings followed where we started the formal coding in a systematic way and gradually developed preliminary descriptions and themes together. In this way we applied a collaborative coding procedure (Saldana, 2009) which involved constant considerations and revisions of the codes (Miles \& Huberman, 1994). Such descriptive phases of analysis build a foundation for an interpretative phase where meaning is extracted from the data (Patton, 2015). We then started looking carefully for recurring regularities in the data material. These regularities revealed patterns that we sorted into categories. During these data-analysis processes credibility was enhanced through the close collaboration between the two researchers who each served as a peer de-briefer for the other throughout the analysis. We engaged in "critical and sustained discussions" (Rossmann \& Rallis, 2003) and thus served as a mirror reflecting the other researcher's responses to the research process.

\section{Findings and Discussion}

Two overall categories were evident in the data material. The category Joint Workplace Experience describes 
the participants' joint experiences of their work practice. The category Inclusion of Joint Workplace Experience in Teaching Practice describes reoccurring regularities of how participants' workplace experience was included in the teaching practice.

\subsection{Joint Workplace Experience}

The participants described their daily work practice in the interviews. Even though they had different professional positions and responsibilities within their companies, the analysis revealed that they had some fairly common joint descriptions of their daily work practice. These descriptions recurred in the data material and are included in the overarching category Joint Workplace Experience. This category covers the participants' joint experience of their work practice, their joint workplace experiences. These are described under two sub-categories: A Changing Interdisciplinary Field and Future Orientation.

\subsubsection{A Changing Interdisciplinary Field}

The data analysis revealed that the participants described their work practice as challenging. They report that they work within a field that is undergoing constant changes when it comes to the development of new technology. The rapid technological developments within the sector and in their daily work mean that the employees have to relate to new and in part unknown technologies. The participants report that they find themselves in a challenging situation as they need to make decisions about the exploitation of energy, plan for renewal of infrastructure and invest in new systems for transmission and distribution of energy systems:

We face many challenges with the new developments within technology since new technologies do not necessarily provide the good answers to the challenges at hand. [...] How do you estimate what is the real value of the different initiatives that the company is considering it might implement? It might be relevant to consider economic theories when making such plans and decisions. There is no lack of smart technologies, but is it smart in ways that secure economic profit?

This utterance reflects that the participants find themselves in a situation where they are uncertain about how they should proceed when solving work tasks. Indeed, they are not certain about how to best make use of the new technologies. It is evident that they need to rely on other professions when calculating and making decisions in their daily work. Schön (2002: p. 187) provides a vivid illustration of engineering as a trade that is undergoing change. Whereas the traditional engineering trade used to focus on "how to build the road", engineers of today need to consider "what road to build".

The participants also report that they have to relate to constant changes in policies governing the energy sector, for example national implementation of transmission and distribution schedules. The participants express that these developments within the energy sector leave the employees in a challenging and unpredictable situation.

In addition to working in a constantly changing field, the participants described the energy sector as having become an interdisciplinary field with traditional engineering, economics, ICT and telecommunication as intersecting areas. Due to this, they experience a need to keep updated within a knowledge field that is much wider than their own professional training:

And although we're not necessarily going to work with all of these subject areas, it's important to get some insight into them... to maybe see opportunities and benefits of all the fields as a combined entity. Because, everything in a manner will become more and more linked together.

I don't know much about power systems. My background is in a different area. I have worked with organizational development and project management. I need a broad understanding of the field. To understand how things are connected with the power system, such as power lines, transformers, radial power stations, phase angles... it is all unknown. For me to be able...but this is a daily work language in which I am a natural part; I encounter it all the time. I need a wider understanding of the sector to perform my work in better ways and to keep up with ongoing professional discussions.

According to the participants' views, the field has undergone major development. They explain that their field has turned into a constantly changing interdisciplinary field. These changes have brought about the need for employees to gain some insight into other professional areas than their own when they make decisions in their daily work practice. They also express that rapidly changing knowledge within the sector adds to the competence 
demands they encounter in their daily work practice.

\subsubsection{Future Orientation}

The participants describe that everyday work involves selecting the best possible solutions for challenges related to exploitation of energy, infrastructure, transmission and distribution of electricity. At the same time, they describe that deciding on solutions is strongly linked to anticipating what the possible future challenges might be within the power industry. In this way the participants see the need to have a future orientation in all issues that they encounter in their daily work. For the participants in our study, one joint workplace experience is the understanding of the need to have a future orientation. The participants express their future orientation in various ways:

I try to look into the future and see what could be happening about three years down the road and beyond.

We have to look at things that are not relevant today but that will be relevant in the future.

These utterances reflect how the participants emphasize the need to dwell on what will happen in the future and that a future orientation involves looking beyond what seem to be reasonable challenges today. The participants are very concerned that any decision made today will have a huge impact on what will be rendered possible in the future. For example, one course participant reflected on the need for his company to make an immediate decision on whether or not to invest in rolling out cables all over their district. Elaborating on the future in terms of involving possible new technological developments would be crucial for the company's current decision to invest in new cables. The participants describe that such considerations are quite complex because when "looking into the future everything becomes more and more integrated...then, when you make a change in one link, changes may affect three or four other links that you did not foresee. So, we need to establish as good an overview of the situation as possible". The need to have a future orientation is evident among the participants. At the same time, this need represents a major challenge in their daily work.

For the participants, the post-graduate course was seen as a much welcomed opportunity to gain insight into academic knowledge at the cutting edge of the research fronts. Such knowledge was seen as the key to being able to predict what might happen in the future. Bearing this in mind, the participants expected opportunities during the course to elaborate on what will happen within any area of the energy sector in the future:

I really saw it (the course) as a chance to get a lot of input on many of the subject areas that we envisage becoming more and more important in the future.

The lecturers should challenge themselves as to what their discipline will be like in the future: My knowledge today — what will it be like in the future?-

The utterances above show that the participants expect the course content to address future challenges. Furthermore, they also expect lecturers to elaborate freely upon a range of possible solutions for any future problem areas.

\subsection{Inclusion of Workplace Experience in Teaching Practice}

Information about the teaching practice was collected through observation of teacher preparations prior to the course and observation of course activities. The interviews also provided information about the teaching practice. The analysis of the data material revealed that the participants described the teaching practice according to considerations they made before attending the course and during course activities, and considerations on learning outcomes at the end of the course. All in all, the descriptions from the observation and interviews are structured along a teaching timeline, including preparations prior to the course, activities during the course and learning outcomes at the end of the course. Furthermore, the analysis revealed that workplace experience was a recurring theme when the participants described the teaching practice. All in all, the recurring descriptions in the data material are covered in the overarching category Inclusion of Workplace Experience in Teaching Practice. In the following we will describe this category by looking into three sub-categories: Preparations and Workplace Experience, Course Activities and Workplace Experience, and End of Course.

\subsubsection{Preparations and Workplace Experience}

The teaching practice can be described according to considerations that the course participants and teachers 
made before start-up. In our study, both the lecturers and course participants undertook preparation activities. For the lecturers, their preparation activities involved the teacher group meeting prior to the post-graduate course to set the course content and consider learning material. They also decided to provide participants with digital access to several videos prior to the course start-up. As preparation prior to the course, the participants were invited to watch the videos. One of the videos provided an outline of the course and introduced some of the main topics, while another video provided general information about the energy sector.

During the interviews the course participants stated that the videos provided a general overview and they appreciated the opportunity to watch them before the course start-up. However, some of the participants point out that it might have been even more helpful if the lecturers had also invited them more directly into the preparation activities:

We (course participants) had very different backgrounds, so it's difficult to say-some topics were especially relevant to me and other topics were especially relevant to others. [...] When the list of participants was final, the course organizers could have proceeded by posing a question prior to the start-up date, asking about which topics YOU want to learn more about. [...] From our (company's) point of view I would have suggested topics relevant to our workplace or topics I presume we will need to deal with at a later stage.

This utterance reflects the participant's opinion that the variety in professional backgrounds called for the introduction of particular measures by the teachers. It is evident that the informant above has strong opinions when it comes to which topics he needs to learn more about: topics that are closely connected to his daily work practice. Furthermore, he suggests that the teachers could have included the course participants when deciding the course content in the preparation phase. Following this, the utterance points out one of the main concerns the course participants had, namely the importance of deciding on content that intersects with the participants' daily work. When the aim is to design a teaching practice that allows participants to construct new knowledge that supports their daily work practice, it is vital to take into consideration both the teachers' and the participants' priorities regarding learning needs.

For the teachers, deciding on a course content that intersects with the participants' workplace experience means coordinating the teachers' views on what constitutes relevant course content and the participants' views on what type of course content will support their daily work practice (Sølvberg, Rismark, \& Fosso, 2014). Such negotiated understandings may provide a shared focus for learning at the onset of any course activity (Rismark \& Sølvberg, 2007; Sølvberg, Rismark, Strømme, \& Hokstad, 2007). A shared focus, “intersubjectivity”, requires that participants establish some common ground. According to Wertsch (1984), intersubjectivity exists between participants who act in the same setting, share the same definition of the situation and know that they share it. We suggest that establishing a shared focus for learning may centre on incorporating the participants' workplace experiences in the course preparations. This may be an essential step towards designing a teaching practice that allows participants to construct new knowledge that supports their daily work practice.

\subsubsection{Course Activities and Workplace Experience}

Lectures were a core activity in the post-graduate course. Teachers with up-front knowledge gave lectures on new developments within energy distribution, infrastructure, transmission and distribution of electricity energy systems. The participants had positive responses to the lectures:

Going to the lectures was like going to a party, because there were clever people everywhere. People who really know what they are talking about and enjoy talking about it. So.... it was a lot of fun to attend the lectures. Most lectures had a high quality.

The participants described the course as enjoyable due to the high quality of the lectures that provided the latest information from upfront research. Analysis of the data material revealed that the teachers provided opportunities for participants to add work experience to any topic during lectures. Participants asked questions, made comments and shared views and opinions during ordinary lectures and teachers always elaborated upon the comments, questions and views that were shared. The participants felt that they could raise questions and make comments at any time:

It (the environment) was very open when it came to questions. Several participants introduced themes and asked questions [...] Asking questions was no problem [...] because the lecturers answered and elaborated 
on the questions continuously. And we could also pursue issues during breaks.

They (the participants) could raise questions that we discussed. And people came from different industries and...there were a lot of discussions around different themes. Future scenarios were discussed. How likely is it....? how realistic is it?...., and so on. But we didn't reach any conclusions, because that's difficult [...] It was a two-way communication, in a way.

When the participants shared experiences from their work practice they also gained insight into upfront issues in other workplaces. Sharing experiences and hearing about other participants' experiences provided a platform for constructing new, shared insights. These opportunities allowed the participants to search for some resemblance between the current course content and their daily work practice. Jackson (2014) suggests that resemblance between learning and application contexts enhances the link between education and work. In this way, searching for resemblance through the sharing of workplace experiences during lectures may be a step towards designing a teaching practice that allows participants to construct new knowledge that supports their daily work practice.

During the course, the teachers also invited the participants to undertake a practical assignment. The participants had to select, investigate and solve a practical challenge from their work practice applying use-case methodology. This is a step-by-step procedure that is followed to select, investigate and solve the practical problem. When the assignment was completed, they shared and discussed the use case with the group. The assignment process provided opportunities to reframe a practical problem and in this process the participants' workplace experiences were incorporated into the academic learning at the university. In this way, opportunities for participants to reframe practical problems from their own workplace support a teaching practice that allows participants to construct new knowledge that supports their daily work practice.

A platform for shared reflections was created when the participants included their workplace experiences in the lectures and when they discussed their use case with the group. According to Schön, reflection is a key to learning, and professionals respond to action by reflecting in the following way: "We may reflect-on-action thinking back on what we have done in order to discover how our knowing in action may have contributed to an unexpected outcome” (2002: p. 26). Reflection-on-action, thinking through a situation after it has happened, can be described in terms of a reflective circle (Kolb, 1984). In this process, learners consciously return to prior experiences, re-evaluate these experiences and decide what could be done differently, and subsequently try out whatever they have decided should be done differently. The teacher needs to play an active role during such reflections and challenges and supports learners' assumptions while validating personally constructed knowledge (Merriam, Caffarella, \& Baumgartner, 2007). Merriam et al. (2007) argue that the key to all descriptions of practical problems is the framing of critical observations and questions as part of the reflection-on-action process. In other words, this is about how professionals reframe practical problems in response to observations and surprises. To foster reflection on experience, links between participants' workplace experiences and coursecontent knowledge must be provided. In this way, opportunities for participants to establish a shared platform for reflections support a teaching practice that allows participants to construct new knowledge that supports their daily work practice.

\subsubsection{End of Course}

A few months after course ended, the participants reported on some its benefits. Lectures were meaningful when new developments were presented and when participants were offered opportunities to share and reflect on workplace experiences. In the interviews, the participants described this as essential for being able to transform knowledge from the course into functional knowledge in the workplace. Eraut (2004) stresses that knowledge, such as concepts, theories and methodology, represents new knowledge in the workplace when it is seen as functional in the workplace. The participants point out two course benefits that were particularly relevant for their work practice. One benefit was the opportunity to incorporate a new methodology, the use-case methodology, for problem solving in the workplace. After the course, several participants had used this methodology as a functional tool during problem solving at their workplace:

It has not been used much here (my workplace) before. I have now started to use it to describe processes. I started using use-case methodology because it's so logical and so simple, it's so easy to get others to understand when applying the use-case method. 
Another course benefit was the renewed ability to perform the job due to an overall increased understanding of the energy sector as a changing interdisciplinary field. This implied that, back at the workplace, the participants reported that they had a broader understanding of the working areas of their colleagues who were specialists within other fields of the energy sector. This benefit was brought about because they were able to engage in extended reflections on workplace based challenges. The participants clearly valued the outcomes from participating in such an interdisciplinary group:

We have slightly different approaches to problems and slightly different understandings of how to resolve the issues. Had we all been power engineers then I think you would have had pretty uniform responses. ... Now, you get a larger totality and a completely different variation in the discussions. If I was alone with only engineers with an electricity background I would not have been able to follow the discussions. Now, they were not so technical and they were understandable and perhaps with a broader view.

As members of this interdisciplinary group, the participants from different professions were encouraged to communicate their arguments in ways that were understandable for colleagues with other professional backgrounds. They needed to go beyond their domain-specific concepts, technical language and jargon when participating in the course activities. At the same time, these communication adjustments opened for the exchange of experiences within the range of energy-sector professions of the course participants. In this way, sharing workplace experiences within the interdisciplinary group was a key to expanding professional learning.

\section{Designing Teaching Practice in Post-Graduate Education: Conclusion and Implications}

This article sets out to explore how teaching practice in post-graduate education may be designed so that participants can construct new knowledge that supports their daily work practice. The findings indicate that the teaching practice in the post-graduate course may be described according to a teaching timeline: from the structure of preparations prior to the course, activities during the course and considerations at the end of the course. The inclusion of participants' workplace experience is a recurring theme along this teaching timeline. The participants in our study had some fairly common joint descriptions of their daily work practice. They explain that their field has turned into a constantly changing interdisciplinary field, and they see the need to have a future orientation in all the issues they encounter in their daily work.

Based on the findings, we suggest a teaching design that includes participants' workplace experience in postgraduate teaching practice. The design is shown in Figure 1.

One of the basic principles in the model is that the course participants' joint workplace experience needs to be included along the teaching timeline. In the figure, the three middle boxes Preparations, Course activities and End of course illustrate the teaching timeline. In the figure, the two boxes called Joint workplace experience intersect along this timeline. This is shown by arrows linking them to the boxes that refer to the teaching timeline. In our study, the participants' joint workplace experience is illustrated by the boxes "A changing interdisciplinary field" and "Future orientation". Other groups of participants attending post-graduate education naturally have other joint understandings of their professional field.

Based on our findings, we suggest that participants' workplace experience needs to be included during preparations prior to the course activities. In the figure this is illustrated by the arrows linking the boxes Joint workplace experience and Preparations. When the aim is to design a teaching practice that allows participants to construct new knowledge that supports their daily work practice, it is vital to take into consideration both the teachers' and the participants' priorities when it comes to learning needs. We suggest that the teachers and participants negotiate a shared focus for learning before starting up the course activities.

Bearing our findings in mind, we also suggest that participants' workplace experiences need to be included during course activities. In the figure this is illustrated by the arrows linking the boxes Joint workplace experience and Course activities. When the aim is to design a teaching practice that allows participants to construct new knowledge that supports their daily work practice, it is vital that the teaching practice encourages participants to reflect, do and share. Opportunities for participants to share experiences and to hear about other participants' experiences provide a platform for constructing new, shared insights through reflections. This involves searching for resemblance between course content and workplace experience and having the opportunity to reframe practical workplace problems. Focus on practical workplace problems may enable participants to 


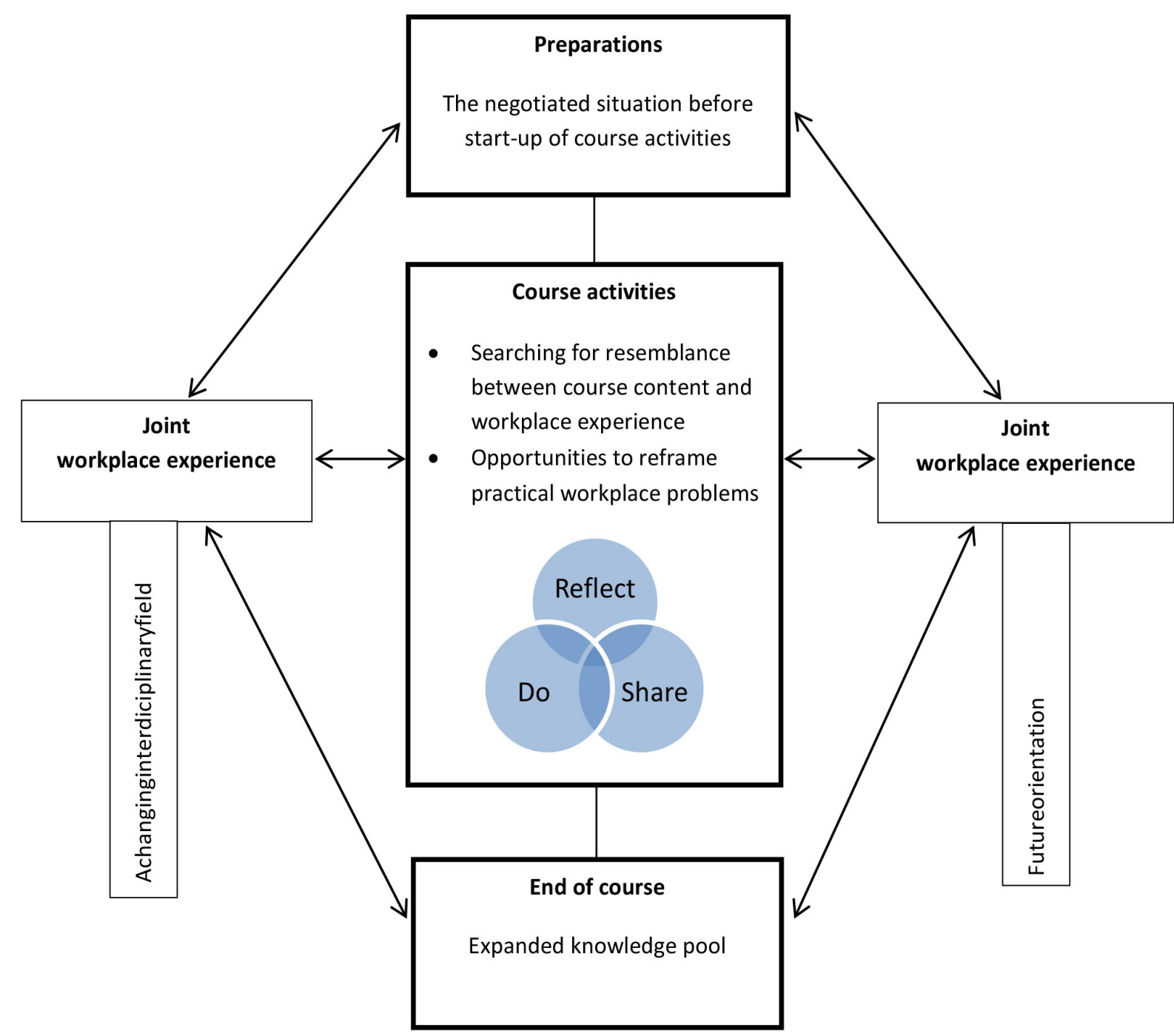

Figure 1. Inclusion of workplace experience in post-graduate teaching practice.

incorporate the practical "doing" of the workplace into the academic learning at the university, activities that involve reflection, sharing and doing overlap in a teaching practice. In the figure this is illustrated by the intersecting circles Reflect, Do and Share. The inclusion of the participants' joint workplace experiences in the teaching practice was also closely connected to the participants' reported benefits at the end of the course. In the figure this is illustrated by the arrows between the boxes Joint workplace experience and End of course.

All in all, we suggest that the teaching design, illustrated in Figure 1, may guide teachers in post-graduate education. Teachers can be assisted in designing a teaching practice to satisfy the competence development needs that workers have. According to this design, we first argue that teachers need to acknowledge the role of experience for learning. Second, they need knowledge about what constitutes joint workplace experience for the specific group of participants in the course they are teaching. Third, the teachers need to include this knowledge in their design of the teaching practice.

Our study has some limitations. The findings stem from a small sample of post-graduate students within the energy sector. New studies with a wider sample of post-graduate students working within other businesses and trades might enable the researchers to search for contrary and parallel cases with reference to broader data material. These limitations notwithstanding, the study provides new insights into how post-graduate courses may be designed to form teaching practices that strengthen the link between workplace experience and university learning. Such insights may be helpful to educators when they design post-graduate courses. 


\section{References}

Dewey, J. (1938). Experience and Education. New York: Collier Books.

Eraut, M. (2004). Transfer of Knowledge between Education and Workplace Settings. In H. Rainbird, A. Fuller, \& A. Munro (Eds.), Workplace Learning in Context (pp. 201-221). London: Routledge.

Fenwick, T. (2003). Learning through Experience: Troubling Orthodoxies and Intersecting Questions. Malabar, FL: Krieger.

Jackson, D. (2014). Modelling Graduate Skill Transfer from University to the Workplace. Journal of Education and Work, 29, 199-231. http://dx.doi.org/10.1080/13639080.2014.907486

Jarvis, P. (1987). Adult Learning in the Social Context. London: Croom Helm.

Jarvis, P. (2006). Towards a Comprehensive Theory of Human Learning. London and New York: Routledge/Falmer Press.

Kolb, A. Y., \& Kolb, D. A. (2005). Learning Styles and Learning Spaces: Enhancing Experiential Learning in Higher Education. Academy of Management Learning and Education, 4, 193-212. http://dx.doi.org/10.5465/AMLE.2005.17268566

Kolb, D. A. (1984). Experiential Learning: Experience as the Source of Learning and Development. Englewood Cliffs, NJ: Prentice Hall.

Merriam, S. B., \& Bierema, L. L. (2014). Adult Learning. Linking Theory and Practice. San Francisco, CA: Jossey-Bass.

Merriam, S. B., Caffarella, R. S., \& Baumgartner, L. M. (2007). Learning in Adulthood. A Comprehensive Guide. San Francisco, CA: Jossey-Bass.

Miles, M. B., \& Huberman, A. M. (1994). Qualitative Data Analysis: An Expanded Sourcebook. Thousand Oaks, CA: Sage Publications.

Morrow, S. L. (2005). Quality and Trustworthiness in Qualitative Research in Counselling Psychology. Journal of Counseling Psychology, 52, 250-260. http://dx.doi.org/10.1037/0022-0167.52.2.250

Noda, A., \& Kim, M. M. (2014). Learning Experiences and Gains from Continuing Professional Education and Their Applicability to Work for Japanese Government Officials. Studies in Higher Education, 39, 927-943.

http://dx.doi.org/10.1080/03075079.2012.754864

Patton, M. Q. (1990). Qualitative Evaluation and Research Methods. Newbury Park, CA: Sage.

Patton, M. Q. (2015). Qualitative Evaluation and Research Methods. Thousand Oaks, CA: Sage.

Rismark, M., \& Sølvberg, A. M. (2007). Effective Dialogues in Driver Education. Accident Analysis and Prevention, 39, 600-605. http://dx.doi.org/10.1016/j.aap.2006.10.008

Rossman, G. B., \& Rallis, S. F. (2003). Learning in the Field: An Introduction to Qualitative Research. Thousand Oaks, CA: Sage.

Roth, W. M. (2010). Learning in Praxis, Learning for Praxis. In S. Billett (Ed.), Learning through Practice. Models, Traditions, Orientations and Approaches (pp. 21-34). Heidelberg London New York: Springer. http://dx.doi.org/10.1007/978-90-481-3939-2__2

Saldana, J. (2009). The Coding Manual for Qualitative Researchers. Los Angeles, CA: Sage Publications.

Schön, D. (1987). Educating the Reflective Practitioner. Toward a New Design for Teaching and Learning in the Professions. San Francisco, CA: Jossey-Bass.

Schön, D. (2002). The Reflective Practitioner. How Professionals Think in Action. Aldershoot: Ashgate Publishing Limited.

Sølvberg, A. M., Rismark, M., \& Fosso, O. B. (2014). A Postgraduate Course for Engineers Finds Its Form. International Journal of Innovation, Creativity and Change, 1, Issue No. 3.

http://www.ijicc.net/index.php/component/content/article/2-aricles-/14-vol1-issue-3-may-2014.html

Sølvberg, A. M., Rismark, M., Strømme, A., \& Hokstad, L. M. (2007). How Mobile Technology Promotes Effective Learning. In Computers and Advanced Technology in Education (pp. 475-480). Anaheim: ACTA Press.

Wertsch, J. W. (1984). The Zone of Proximal Development: Some Conceptual Issues. In B. Rogoff, \& J. W. Wertsch (Eds.), Children's Learning in the "Zone of Proximal Development”. New Directions for Child Development (pp. 7-18). San Francisco, CA: Jossey-Bass. 


\section{Submit or recommend next manuscript to SCIRP and we will provide best service for you:}

Accepting pre-submission inquiries through Email, Facebook, LinkedIn, Twitter, etc.

A wide selection of journals (inclusive of 9 subjects, more than 200 journals)

Providing 24-hour high-quality service

User-friendly online submission system

Fair and swift peer-review system

Efficient typesetting and proofreading procedure

Display of the result of downloads and visits, as well as the number of cited articles

Maximum dissemination of your research work

Submit your manuscript at: http://papersubmission.scirp.org/ 